\title{
Burden of respiratory syncytial virus infections in China: Systematic review and meta-analysis
}

Yaowen Zhang', Lichao Yuan², Yongming Zhang ${ }^{3}$, Xiuping Zhang ${ }^{4}$, Minghuan Zheng ${ }^{5}$, Moe H Kyaw ${ }^{6}$

${ }^{1} 1$ Infection Management and Disease Prevention Department, China-Japan Friendship Hospital, Beijing, China

${ }^{2}$ Department of Infectious Diseases, China-Japan Friendship Hospital, Beijing, China ${ }^{3}$ Department of Respiratory Diseases, ChinaJapan Friendship Hospital, Beijing, China

${ }^{4}$ China-Japan Friendship Clinical College, Beijing University of Chinese Medicine, Beijing, China

${ }^{5}$ Sanofi Pasteur, Beijing, China

${ }^{6}$ Sanofi Pasteur, Swiftwater, PA, USA
Background: Respiratory syncytial virus (RSV) is the most important cause of acute respiratory tract infection (ARTI) related morbidity and mortality worldwide. However, the disease burden due to RSV has not been systematically summarized in China.

Method: A systematic search was performed in the Chinese BioMedical Database (CBM), China National Knowledge Infrastructure (CNKI), Wanfang database and PubMed to identify available published RSV studies in China.

Results: A total of 489641 patients with ARTIs from 135 studies were included in the analysis. Among patients with ARTIs, RSV accounted for $18.7 \%$ (95\% confidence interval CI 17.1-20.5\%). The prevalence of RSV was highest in infants (26.5\%, 95\% CI 23.7-29.5\%) and lowest in those aged $\geqq 16$ years $(2.8 \%, 95 \%$ CI 1.3-6.1). A higher prevalence of RSV was seen in inpatients (22\%, 95\% CI 19.9-24.2\%) than in outpatients (14\%, 95\% CI 9.6-19.9\%). RSV type A accounted for 63.1\% (95\% CI 52.3-72.8\%) of all RSV infections. RSV infections occurred mainly in winter and spring. The most common clinical manifestations were cough, production of sputum, wheezing and fever.

Conclusion:RSV is the leading cause of viral ARTIs in China, particularly in infants and young children. Our findings are valuable for guiding the selection of appropriate therapies for ARTIs and implementation of preventive measures against RSV infections. Our data further supports the development of a successful RSV vaccine as a high priority.

\section{Correspondence to:}

Dr Moe H Kyaw

Sanofi Pasteur

1 Discovery Avenue

Swiftwater, PA 18371

USA

moe.kyaw@sanofipasteur.com
Acute respiratory tract infections (ARTIs) are an important cause of morbidity and mortality among children under the age of 5 years [1,2], with the highest number of deaths occurring in developing countries [3]. In China, pneumonia is the leading cause of deaths in children under 5 years old with an estimated $>30000$ deaths annually [4]. Viruses have been considered as the most frequent causes of ARTIs. The predominant viruses associated with ARTIs in children include respiratory syncytial virus (RSV), influenza virus (IV), parainfluenza virus (PIV), human rhinovirus (HRV) and adenovirus (ADV) $[5,6]$.

RSV is the leading cause of ARTIs in early childhood. It is estimated that 33.8 million new episodes of RSV-associated acute lower respiratory infection 
(ALRI) occurred worldwide in children younger than 5 years, with at least 3.4 million episodes representing severe RSVassociated ALRI necessitating hospital admission [7]. The pattern of RSV infections is variable and related to season, socio-demographic and characteristics of study populations.

China has the largest child population and has substantial differences in climate from region to region. It has a variety of temperature and rainfall zones, including continental monsoon areas. The total population of children aged 14 years or younger is estimated to be 230 million. Although the epidemiology of RSV infections has been studied in cities such as Beijing, Chongqing and Lanzhou [8-10], few RSV studies in China have been published in English. Therefore, we performed a systematic review and metaanalysis of published studies to evaluate the epidemiology of RSV infections in patients with ARTIs.

A better understanding of the epidemiology of RSV infections plays a key role for the prevention, control and treatment of ARTIs. The objective of this systematic review and meta-analysis was to evaluate the etiology, serotypes, clinical features, age distribution and seasonality associated with RSV infections in China.

\section{METHODS}

\section{Search strategy}

A systematic search was performed in indexed databases, including Chinese BioMedical Database (CBM), China National Knowledge Infrastructure (CNKI), Wanfang database and PubMed to identify available RSV studies in China. The following search terms were used: RSV or syncytial virus. Taking into account the quality of studies, high quality publications from the Chinese core journals (2014 edition) [11] were considered in the final analysis. The Library of Perking University evaluates all Chinese journals every four years and excludes lower quality journals using the quality measurement similar to the impact factors. To obtain recent data, the search strategy was limited to publications dated from January 2010 to Mar 2015. Details of the search strategy are presented in Appendix S1 in Online Supplemen-

\section{tary Document.}

\section{Inclusion and exclusion criteria}

To be included, the following criteria had to be fulfilled: 1) studies in humans; 2) studies in patients with ARTIs; 3) studies that had at least one following outcome: etiology of acute respiratory infections; seasonality; gender; age group; serotypes; clinical features; 4) studies published in Chinese or English.

Publications were excluded if they were: 1) animal experiments or basic research (examples, studies focus on prin- ciples or mechanisms using cells and tissues); 2) case reports, systematic review or meta-analysis; 3 ) replicates (when the same population was studied in more than one publication, only the latest one or the one with the most complete data was considered for the meta-analysis).

ARTIs was defined as patients who were present of one or more respiratory symptoms, including watery eyes, rhinorrhea, nasal congestion or sinus congestion, otitis media, pharyngitis, cough, sore throat, sneezing, headache, and muscle pain. Meanwhile, patients had at least one symptom during acute infection, with high fever (body temperature $\geq 38^{\circ} \mathrm{C}$ ) or chillness or normal/low leukocyte count or who were diagnosed with pneumonia by chest radiography previously. Chest radiography was conducted according to the clinical situation of the patient, and pneumonia was defined as an acute illness with radiographic pulmonary shadowing (at least segmental or in one lobe) by chest radiography.

\section{Literature screening and data extraction}

Literature reviewers were divided into two parallel groups. Using the set criteria of inclusion and exclusion, the reviewers independently screened the literature by title, keyword and abstract. Any disagreement was solved by a third reviewer. If they were not sure whether the study should be included, the decision was made based on further review of the full texts. NoteExpress 2 (Aegean Software Corporation, Shanghai, China) was used for the bibliography management.

Two parallel groups independently extracted the following data from eligible studies: general information, methodological quality and outcome data. Inconsistencies between two groups were checked after data extraction. Any disagreements were solved by the third reviewer.

\section{Quality assessment}

This meta-analysis included various types of studies with different outcomes. Therefore, no pre-existing scale is directly suitable for the assessment. The 5-item specific rating scale was developed to assess the quality of studies. These included 1) Did the study report patients' information? 2) Did the study report diagnosis criteria of acute respiratory infection? 3) Did the study report specimen collection methods? 4) Did the study report pathogen detection methods? 5) Did the study report statistical methods? Each item was scored on three scales; 0 indicating low quality, 1 indicating medium quality, and 2 indicating high quality. The score for each item was then added to give a composite score for the study, with a highest total score of 10. If the total score was equal to or greater than 8 , we regarded the study as "good" quality. 


\section{Statistical analysis}

The MetaAnalyst (Beta 3.13; Tufts Evidence-based Practice Center, Boston, USA) was used to conduct meta-analyses for pooled proportions and odds ratios. Considering heterogeneity across all studies, we chose a random-effects model to carry out meta-analysis using Der-Simonian Laird method. The publication bias was determined via Stata 12.0 (StataCorp LP, Texas, USA) using an Egger's test. Meta-analysis for combining the results of studies was weighted to provide the balanced results of all included studies.

\section{RESULTS}

\section{Selection of studies}

Of the total of 4852 studies identified through the databases, 135 studies were included in the analysis (Figure 1). Of the 135 studies, 123 studies were in children less than 16 years old and the remaining studies were in both children and adults. Of the 135 studies, 19 studies were published in English. The detailed information about author, publication year, province, age, specimen type, detection methodology, number of specimen and study outcomes are listed in Appendix S2 in Online Supplementary Document.

For the 135 studies, the quality evaluation score ranged from 5 to 10 points, with a mean \pm standard deviation of $7.7 \pm 1.3$. There were 80 studies with a score of $\geqq 8$. The summary of quality assessment is listed in Appendix S3 in Online Supplementary Document.

\section{Etiology}

The overall positivity rate of RSV among patients with ARTIs was $18.7 \%$ (95\% CI 17.1-20.5\%), followed by HRV, human bocavirus (HBoV), IV, PIV, human metapneumovirus (HMPV), enterovirus, ADV and human coronavirus (HCoV). (Table 1).

Table 1. Etiology of acute respiratory infection in all ages

\begin{tabular}{|c|c|c|c|c|}
\hline VIRUS & $\begin{array}{l}\text { No. ARTICIES } \\
\text { INCLUDED }\end{array}$ & VIRUS-POSITIVE & $\begin{array}{c}\text { Total } \\
\text { PATIENTS }\end{array}$ & $\begin{array}{l}\text { PositIVE RAIE } \\
(\%, 95 \% \text { CI) }\end{array}$ \\
\hline RSV & 132 & 81747 & 489641 & $18.7(17.1-20.5)$ \\
\hline Rhinovirus & 36 & 3647 & 31605 & $11.5(9.8-13.5)$ \\
\hline $\mathrm{HBoV}$ & 45 & 5899 & 110345 & $6.8(5.5-8.5)$ \\
\hline IV & 95 & 17115 & 262089 & $6.5(5.4-7.7)$ \\
\hline PIV & 97 & 17515 & 264538 & $6.4(5.6-7.2)$ \\
\hline HMPV & 59 & 5935 & 130620 & $4.3(3.6-5.1)$ \\
\hline Enterovirus & 16 & 923 & 17689 & $4.0(2.8-5.6)$ \\
\hline Adenovirus & 96 & 9618 & 275380 & $3.4(2.9-3.9)$ \\
\hline $\mathrm{HCoV}$ & 39 & 1544 & 66048 & $2.6(2.0-3.4)$ \\
\hline
\end{tabular}

RSV - respiratory syncytial virus, PIV - parainfluenza virus, IV - influenza virus, HMPV - human metapneumovirus, HBoV - human bocavirus; $\mathrm{HCoV}$, Human coronavirus, $\mathrm{CI}$ - confidence interval

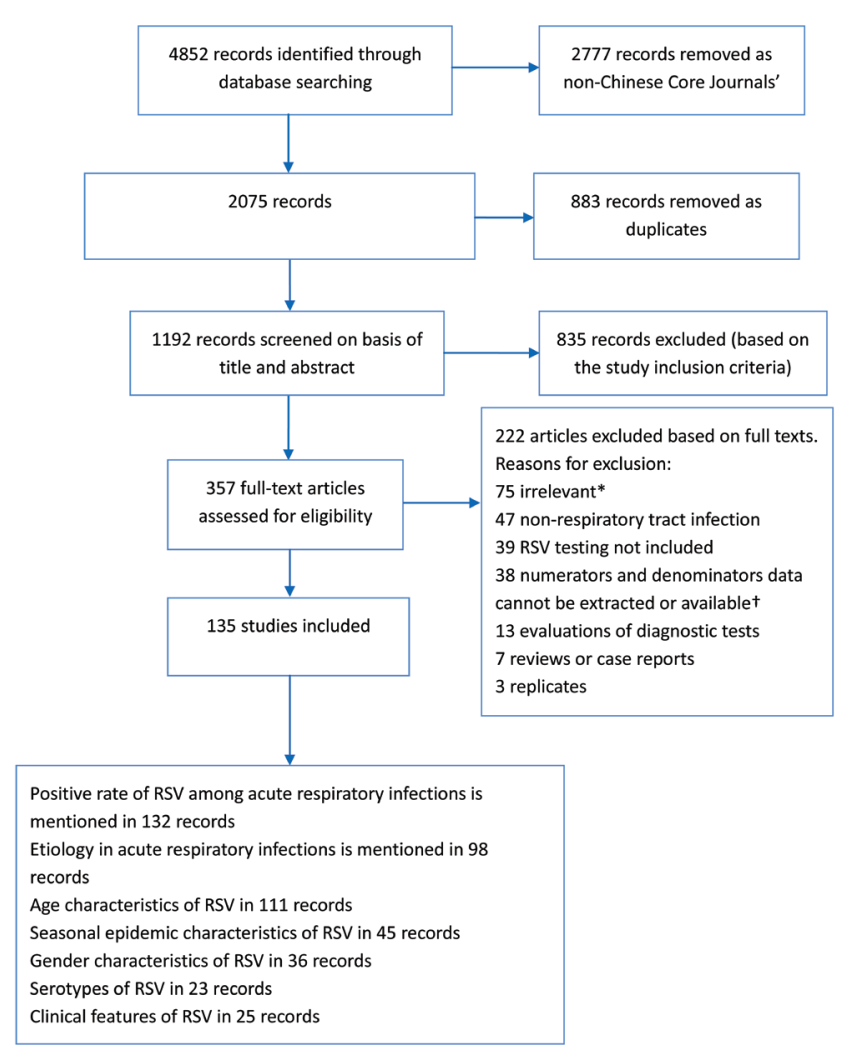

Figure 1. Flow diagram of literature search and selection. * Including: 1) Did not discuss respiratory tract infections or respiratory syncytial virus; or 2) only as background to discuss; or 3) used the abbreviation "RSV", but not referring to respiratory syncytial virus. †These studies reported/ included charts or risk ratios and the numerators and denominators were not available.

The prevalence of RSV was stratified into inpatients, outpatients, inpatients/outpatients and unknown category. RSV was found most frequently among inpatients $22.0 \%$ (95\% CI 19.9-24.2\%), followed by inpatients/outpatients, outpatients and unknown (Table 2).

\section{Seasonal characteristics}

A total of 45 studies reported the seasonality of RSV infections. Of these 45 studies, 28 studies reported monthly isolation rates and the remaining 17 studies reported quarterly. The peak of RSV infections mainly occurred in winter and spring (Table 3).

\section{Gender characteristics}

A total of 36 studies reported gender characteristics of RSV infections. Among 96694 male patients, RSV was positive in 17163 patients (20.4\%, 95\% CI 16.6-24.8\%). Among 54958 female patients, RSV was positive in 8364 (19.9\%, 95\% CI 16.0-24.4\%). 
Table 2. Positive rate of RSV infection in acute respiratory tract infected patients

\begin{tabular}{|c|c|c|c|c|}
\hline & $\begin{array}{l}\text { No. } \\
\text { ARTICLES } \\
\text { INCLUDED }\end{array}$ & $\begin{array}{l}\text { Virus- } \\
\text { POSITIVE }\end{array}$ & $\begin{array}{l}\text { Total } \\
\text { PATIENTS }\end{array}$ & $\begin{array}{l}\text { Positive rate } \\
(\%, 95 \% \text { CI) }\end{array}$ \\
\hline \multicolumn{5}{|l|}{ Settings: } \\
\hline Inpatient & 86 & 67319 & 366386 & $22.0(19.9-24.2)$ \\
\hline Outpatient & 9 & 1061 & 9229 & $14.0(9.6-19.9)$ \\
\hline Inpatient/outpatient & 45 & 8779 & 67826 & $15.8(12.1-20.2)$ \\
\hline Unspecified & 95 & 4568 & 46200 & $11.4(7.4-17.1)$ \\
\hline Total & 132 & 81747 & 489641 & $18.7(17.1-20.5)$ \\
\hline \multicolumn{5}{|l|}{ Age groups: } \\
\hline $0-6 \mathrm{~m}$ & 45 & 12522 & 43222 & $29.9(26.2-33.8)$ \\
\hline $0-1 y$ & 65 & 29607 & 113386 & $26.5(23.7-29.5)$ \\
\hline $0-3 y$ & 55 & 27544 & 130152 & $23.7(20.9-26.9)$ \\
\hline $0-6 y$ & 47 & 17854 & 121717 & $19.5(16.0-19.6)$ \\
\hline $0-16 y$ & 72 & 57193 & 351426 & $17.7(5.5-8.5)$ \\
\hline$\geq 16 y$ & 7 & 440 & 18781 & $2.8(1.3-6.1)$ \\
\hline \multicolumn{5}{|l|}{$\begin{array}{l}\text { Inpatients only by } \\
\text { age groups: }\end{array}$} \\
\hline $0-6 \mathrm{~m}$ & 31 & 10690 & 35592 & $32.4(27.7-37.4)$ \\
\hline $0-1 y$ & 44 & 25259 & 97542 & $34.4(28.9-40.4)$ \\
\hline $0-3 y$ & 37 & 20789 & 99951 & $24.3(20.6-28.3)$ \\
\hline $0-6 y$ & 28 & 12446 & 88248 & $19.8(16.4-23.7)$ \\
\hline $0-16 y$ & 45 & 46128 & 270359 & $20.0(17.9-22.3)$ \\
\hline$\geq 16 y$ & 3 & 174 & 8604 & $2.8(0.8-9.8)$ \\
\hline \multicolumn{5}{|l|}{ Regions: } \\
\hline Northeast & 2 & 285 & 3003 & $9.5(8.5-10.6)$ \\
\hline North China & 18 & 2203 & 26710 & $10.9(6.3-18.4)$ \\
\hline South China & 23 & 10625 & 96413 & $15.7(13.2-18.6)$ \\
\hline East China & 44 & 50001 & 273312 & $17.6(15.3-20.2)$ \\
\hline Central China & 14 & 2978 & 16346 & $22.5(16.8-29.5)$ \\
\hline Northwest & 9 & 1523 & 5010 & $27.6(21.3-34.9)$ \\
\hline Southwest & 20 & 10375 & 35970 & $28.7(25.7-32.0)$ \\
\hline Multi-regions & 2 & 3757 & 32877 & $14.7(6.6-29.6)$ \\
\hline \multicolumn{5}{|l|}{$\begin{array}{l}\text { Detection } \\
\text { methodology } \dagger\end{array}$} \\
\hline IF & 51 & 41201 & 230033 & $17.0(14.4-20.0)$ \\
\hline PCR & 73 & 32814 & 201063 & $19.9(17.9-22.1)$ \\
\hline Others & 8 & 7732 & 58545 & $20.1(15.8-25.3)$ \\
\hline
\end{tabular}

$\dagger^{*} \mathrm{PCR}$ - polymerase chain reaction, IF - immunofluorescence, Others - refers to PCR/IF and RVP Fast, y - year, $\mathrm{m}$ - month, CI - confidence interval
Table 3. Seasonal epidemic characteristics of RSV infection among acute respiratory infected patients

\begin{tabular}{|c|c|c|c|c|}
\hline $\begin{array}{l}\text { Montih/ } \\
\text { SEASON* }\end{array}$ & $\begin{array}{l}\text { No. } \\
\text { ARTICLES } \\
\text { INCLUDED }\end{array}$ & RSV-POSITIVE & $\begin{array}{l}\text { TotAL } \\
\text { PATIENTS }\end{array}$ & $\begin{array}{l}\text { Positive rate (\%) (95\% } \\
\text { CONFIDENCE INTERVAL) }\end{array}$ \\
\hline Jan & 17 & 1150 & 4672 & $24.7(15.2-37.5)$ \\
\hline Feb & 17 & 1094 & 4311 & $25.1(17.1-35.4)$ \\
\hline Mar & 17 & 849 & 4003 & $19.5(13.5-27.4)$ \\
\hline Apr & 16 & 504 & 3174 & $17.4(13.5-22.3)$ \\
\hline May & 15 & 181 & 2551 & $8.7(6.1-12.3)$ \\
\hline Jun & 14 & 135 & 2945 & $5.5(3.1-9.4)$ \\
\hline Jul & 14 & 105 & 2805 & $4.5(3 .-6.8)$ \\
\hline Aug & 13 & 163 & 2605 & $7.0(4.5-10.7)$ \\
\hline Sep & 14 & 183 & 2511 & $6.4(3.6-11.3)$ \\
\hline Oct & 16 & 254 & 2935 & $7.5(4.2-13.1)$ \\
\hline Nov & 17 & 597 & 3522 & $14.4(8.8-22.5)$ \\
\hline Dec & 17 & 1049 & 3954 & $26.2(17.9-36.8)$ \\
\hline Spring & 27 & 5627 & 37738 & $13.9(11.1-17.4)$ \\
\hline Summer & 27 & 2008 & 31716 & $5.3(3.7-7.6)$ \\
\hline Autumn & 27 & 4204 & 28223 & $11.8(8.2-16.8)$ \\
\hline Winter & 27 & 9774 & 32937 & $22.7(17.4-29.1)$ \\
\hline
\end{tabular}

*Spring - 1 March to 31 May, Summer - 1 June to 31 August, Autumn - 1 September to 30 November, Winter - 1 December to 28/29 February.

Table 4. Clinical characteristics of RSV related acute respiratory infected patients

\begin{tabular}{|c|c|c|c|c|}
\hline $\begin{array}{l}\text { CuniCal } \\
\text { ChARACTERISTICS }\end{array}$ & $\begin{array}{l}\text { Nlo. of } \\
\text { ARTICIES } \\
\text { INCLUDED }\end{array}$ & $\begin{array}{l}\text { SyMPTOMATIC } \\
\text { PATIENTS }\end{array}$ & $\begin{array}{l}\text { RSV INFECTED } \\
\text { PATIENTS }\end{array}$ & Percent (95\% CI) \\
\hline Cough & 24 & 9880 & 11194 & 93.9 (91.0-96.0) \\
\hline Expectoration & 6 & 1578 & 2316 & $66.3(43.8-83.2)$ \\
\hline Wheeze & 13 & 1768 & 2778 & $65.7(56.5-73.8)$ \\
\hline Fever & 22 & 3738 & 10018 & $43.0(37.5-48.7)$ \\
\hline Rhinorrhea & 8 & 1621 & 5669 & $42.7(31.6-54.6)$ \\
\hline Cyanosis & 9 & 1346 & 4318 & $38.9(15.8-68.2)$ \\
\hline Tachypnea & 11 & 2024 & 7737 & $32.2(15.7-54.9)$ \\
\hline Diarrhea & 7 & 838 & 5272 & $18.8(11.4-29.5)$ \\
\hline Dyspnoea & 8 & 1707 & 7918 & $12.8(5.0-28.9)$ \\
\hline
\end{tabular}

\section{Sensitivity analysis and publication bias}

The conclusions remained robust and the outcomes did not alter significantly when only 'good' quality studies were evaluated in the sensitivity analysis. The overall RSV positivity rates were $19.7 \%$ (95\% CI 17.7-21.9\%) in all patients ( $n=79), 22.7 \%$ (95\% CI 20.2-25.3\%) in inpatients $(\mathrm{n}=53)$, and $13.8 \%$ (95\% CI 8.3-22.0\%) in outpatients $(n=5)$.

Publication bias was tested using the Egger's test. No publication bias was detected when verifying the 132 publications that reported RSV positive rates in all patients $(-0.27$, 95\% CI -1.19 to $-0.65, P=0.563)$. 


\section{DISCUSSION}

RSV is the most common viral cause of ARTIs in developed and developing countries $[7,12]$. However, the available epidemiological data on RSV in China has not been systematically summarized in English. Our results highlight that RSV is the leading cause of viral ARTIs in China.

The burden of respiratory viral infections is difficult to measure and is likely to differ from country to country due to several factors such as socio-demographic distribution, seasonal variation, study design and diagnostic techniques. In our study, RSV was the most frequently detected pathogen among patients with ARTIs in all age groups studied. Consistent with other studies, RSV and HRV were the most prevalent viruses in children $[2,13,14]$.

In the present study, only 12 studies reported the RSV infections in adult patients and the remaining 123 studies were in children. Infants aged $\leq 1$ year were at higher risk of RSV associated ARTIs, compared with those in other age groups. This is consistent with the previous reports of RSV in both developed and developing countries $[7,12,15,16]$. The data show that RSV accounted for nearly $30 \%$ of all ARTIs in infants. Efforts to prevent RSV infections in infants can lead to a substantial reduction of RSV associated morbidity, mortality and medical costs in China. Further evidence of RSV disease burden can be established by adding RSV studies in existing influenza surveillance systems.

The relation between RSV infections and climate has been well documented $[17,18]$. In regions with persistently warm temperatures and high humidity, RSV activity is continuous throughout the year, peaking in summer and early autumn. In temperate climates, RSV activity is maximal during winter, correlating with lower temperatures. In areas where temperatures remain colder throughout the year, RSV activity also occurs almost continuously $[17,18]$. Most areas of China have a temperate climate. We found that the peak of RSV activity mainly occurred during winter and spring in China, which is similar to the previous reports [19-21]. This pattern of seasonality corresponds to the cold and dry seasons. However, we are unable to report regional differences in RSV activity due to limited data availability.

Based on genetic and antigenic variations in structural proteins, RSV isolates are subdivided into two major antigenic types (A and B). Both types are associated with mild to severe ARTIs [22-24]. Studies have shown that type A and $\mathrm{B}$ viruses co-circulate in the same area during epidemic periods and have various patterns of predominance [2528]. However, the prevalence of each type may shift yearly and can vary among different communities [28-30]. Our analysis showed that type A was the predominant serotype accounting for $63.1 \%$ of all RSV infections. However, it is difficult to know how the sero-epidemiological trend changed in the recent years in China. This is because the study periods and locations varied substantially among included studies.

The studies we included differed in their methods of sampling and case-definition. Therefore, caution should be taken when interpreting the results. In our study, only 42 studies presented detailed criteria for case-definition. In addition, only 54 out of the 135 included studies used immunofluorescence for RSV detection. RSV was identified less frequently (17.0\%) if only the results of studies based on immunofluorescent detection were included. In comparison with immunofluorescence, molecular diagnostics are more sensitive and specific $[31,32]$. In recent years, the introduction of nucleic acid based diagnostic tests has markedly improved our understanding of viral etiology among ARTI patients [33]. Therefore, the real burden of RSV in China is likely to be higher than our findings if more sensitive diagnostic methods are used.

These differences in case definitions and diagnostic techniques are likely to have impacted the results. Therefore, a random effects model was applied to take into account the heterogeneity between studies resulting in wider 95\% CIs with more conservative estimates of the overall results [34]. In addition, the etiology data in the present study should be interpreted with caution. This is because restricting RSV to the title and abstract in the search criteria is a potential source of bias and might not be representative of all studies reporting other viruses. However, all included studies in current review tested for multiple viruses. Therefore, it is reasonable to assume that the use of correct denominator and numerators allow us to present the useful and informative etiology data available in these studies.

In conclusion, this systematic review and meta-analysis showed that RSV is the leading cause of ARTIs in China, particularly among infants. Our findings are valuable for guiding the selection of appropriate therapies for ARTIs and implementation of preventive measures against RSV infections. Despite the disease burden, no effective RSV vaccine is currently available. Our data further supports the development of a successful RSV vaccine as a high priority. 
Funding: Sanofi Pasteur funded this study.

Authorship declaration: Study design (YZ, MHK); data collection (YZ, LY, YZ, XZ); data analysis (YZ, LY, YZ, XZ); data interpretation (YZ, LY, YZ, XZ MZ, MHK); development of initial draft of manuscript (YZ, MHK), critical revisions for intellectual content of manuscript (YZ, LY, YZ, XZ, MZ, MHK); study supervision (YZ, MZ, MHK). All authors reviewed and approved the final draft of manuscript.

Competing interests: All authors have completed the Unified Competing Interest form at www.icmje.org/coi_disclosure.pdf (available on request from the corresponding author). $\mathrm{MZ}$ and MHK are employees of Sanofi Pasteur.

1 Tregoning JS, Schwarze J. Respiratory viral infections in infants: causes, clinical symptoms, virology, and immunology. Clin Microbiol Rev. 2010;23:74-98. Medline:20065326 doi:10.1128/CMR.00032-09

2 Rudan I, Chan KY, Zhang JSF, Theodoratou E, Feng XL, Salomon JA, et al. Causes of deaths in children younger than 5 years in China in 2008. Lancet. 2010;375:1083-9. Medline:20346815 doi:10.1016/S01406736(10)60060-8

3 Williams BG, Gouws E, Boschi-Pinto C, Bryce J, Dye C. Estimates of world-wide distribution of child deaths from acute respiratory infections. Lancet Infect Dis. 2002;2:25-32. Medline:11892493 doi:10.1016/S14733099(01)00170-0

4 Mulholland K, Temple B. Causes of death in children younger than 5 years in China in 2008. Lancet. 2010;376:89-90. Medline:20621232 doi:10.1016/S0140-6736(10)61073-2

5 Hammond S, Chenever E, Durbin JE. Respiratory virus infection in infants and children. Pediatr Dev Pathol. 2007;10:172-80. Medline:17535096 doi:10.2350/07-02-0238.1

6 Sloots TP, Whiley DM, Lambert SB, Nissen MD. Emerging respiratory agents: new viruses for old diseases? J Clin Virol. 2008;42:233-43. Medline:18406664 doi:10.1016/j.jcv.2008.03.002

7 Nair H, Nokes DJ, Gessner BD, Dherani M, Madhi SA, Singleton RJ, et al. Global burden of acute lower respiratory infections due to respiratory syncytial virus in young children: a systematic review and meta-analysis. Lancet. 2010;375:1545-55. Medline:20399493 doi:10.1016/S0140-6736(10)60206-1

8 Xiang Z, Gonzalez R, Ren L, Xiao Y, Chen L, Zhang J, et al. Prevalence and clinical characteristics of human respiratory syncytial virus in Chinese adults with acute respiratory tract infection. J Med Virol. 2013;85:34853. Medline:23192884 doi:10.1002/jmv.23467

9 Zhang RF, Jin Y, Xie ZP, Liu N, Yan KL, Gao HC, et al. Human respiratory syncytial virus in children with acute respiratory tract infections in China. J Clin Microbiol. 2010;48:4193-9. Medline:20810776 doi:10.1128/ JCM.00179-10

10 Zhang ZY, Du LN, Chen X, Zhao Y, Liu EM, Yang XQ, et al. Genetic variability of respiratory syncytial viruses (RSV) prevalent in Southwestern China from 2006 to 2009: emergence of subgroup B and A RSV as dominant strains. J Clin Microbiol. 2010;48:1201-07. Medline:20147636 doi:10.1128/JCM.02258-09

11 The Library of Perking University. Chinese core journals (2014 edition). Available: http://www.zzqklm.com/w/ qz/15567.html. Accessed: 2 November 2015.

12 Hall CB, Weinberg GA, Iwane MK, Blumkin AK, Edwards KM, Staat MA, et al. The burden of respiratory syncytial virus infection in young children. N Engl J Med. 2009;360:588-98. Medline:19196675 doi:10.1056/ NEJMoa0804877

13 Do AH, van Doorn HR, Nghiem MN, Bryant JE, Hoang TH, Do QH, et al. Viral etiologies of acute respiratory infections among hospitalized Vietnamese children in Ho Chi Minh City, 2004-2008. PLoS ONE. 2011;6:e18176. Medline:21455313 doi:10.1371/journal.pone.0018176

14 Wang W, Cavailler P, Ren P, Zhang J, Dong W, Yan H, et al. Molecular monitoring of causative viruses in child acute respiratory infection in endemo-epidemic situations in Shanghai. J Clin Virol. 2010;49:211-8. Medline:20855230 doi:10.1016/j.jcv.2010.08.005

15 Broor S, Parveen S, Bharaj P, Prasad VS, Srinivasulu KN, Sumanth KM, et al. A prospective three-year cohort study of the epidemiology and virology of acute respiratory infections of children in rural India. PLoS ONE. 2007;2:e491. Medline:17551572 doi:10.1371/journal.pone.0000491

16 Pavia AT. Viral infections of the lower respiratory tract: old viruses, new viruses, and the role of diagnosis. Clin Infect Dis. 2011;52:(Suppl 4):S284-9. Medline:21460286 doi:10.1093/cid/cir043

17 Yusuf S, Piedimonte G, Auais A, Demmler G, Krishnan S, Van Caeseele P, et al. The relationship of meteorological conditions to the epidemic activity of respiratory syncytial virus. Epidemiol Infect. 2007;135:1077-90. Medline:17346359 doi:10.1017/S095026880600776X

18 du Prel JB, Puppe W, Gröndahl B, Knuf M, Weigl JA, Schaaff F, et al. Are meteorological parameters associated with acute respiratory tract infections? Clin Infect Dis. 2009;49:861-8. Medline:19663691 doi:10.1086/605435 
19 Rodríguez-Auad JP, Nava-Frías M, Casasola-Flores J, Johnson KM, Nava-Ruiz A, Pérez-Robles V, et al. The epidemiology and clinical characteristics of respiratory syncytial virus infection in children at a public pediatric referral hospital in Mexico. Int J Infect Dis. 2012;16:e508-13. Medline:22525227 doi:10.1016/j.ijid.2012.03.001

20 Manoha C, Espinosa S, Aho SL, Huet F, Pothier P. Epidemiological and clinical features of hMPV, RSV and RVs infections in young children. J Clin Virol. 2007;38:221-6. Medline:17241812 doi:10.1016/j.jcv.2006.12.005

21 Zhang XL, Shao XJ, Wang J, Guo WL. Temporal characteristics of respiratory syncytial virus infection in children and its correlation with climatic factors at a public pediatric hospital in Suzhou. J Clin Virol. 2013;58:66670. Medline:24176283 doi:10.1016/j.jcv.2013.09.027

22 Martinello RA, Chen MD, Weibel C, Kahn JS. Correlation between respiratory syncytial virus genotype and severity of illness. J Infect Dis. 2002;186:839-42. Medline:12198620 doi:10.1086/342414

23 Mentel R, Ilgert U, Wegner U, Zimmerman K, Bruns R, Gurtler L. Molecular and clinical characteristics of respiratory syncytial virus infections in hospitalized children. Med Microbiol Immunol (Berl). 2005;194:67-71. Medline:14722763 doi:10.1007/s00430-003-0215-9

24 Oliveira TF, Freitas GR, Ribeiro LZ, Yokosawa J, Siqueira MM, Portes SA, et al. Prevalence and clinical aspects of respiratory syncytial virus A and B groups in children seen at Hospital de Clinicas of Uberlandia, MG, Brazil. Mem Inst Oswaldo Cruz. 2008;103:417-22. Medline:18797752 doi:10.1590/S0074-02762008000500002

25 Kuroiwa Y, Nagai K, Okita L, Yui I, Kase T, Nakayama T, et al. A phylogenetic study of human respiratory syncytial viruses group A and B strains isolated in two cities in Japan from 1980 to 2002. J Med Virol. 2005;76:2417. Medline: 15834873 doi:10.1002/jmv.20348

26 Parveen S, Sullender WM, Fowler K, Lefkowitz EJ, Kapoor SK, Broor S. Genetic variability in the G protein gene of group A and B respiratory syncytial viruses from India. J Clin Microbiol. 2006;44:3055-64. Medline:16954227 doi:10.1128/JCM.00187-06

27 Venter M, Madhi SA, Tiemessen CT, Schoub BD. Genetic diversity and molecular epidemiology of respiratory syncytial virus over four consecutive seasons in South Africa: identification of new subgroup A and B genotypes. J Gen Virol. 2001;82:2117-24. Medline:11514720 doi:10.1099/0022-1317-82-9-2117

28 Scott PD, Ochola R, Ngama M, Okiro EA, Nokes DJ, Medley GF, et al. Molecular epidemiology of respiratory syncytial virus in Kilifi District, Kenya. J Med Virol. 2004;74:344-54. Medline:15332285 doi:10.1002/ jmv.20183

29 Sato M, Saito R, Sakai T, Sano Y, Nishikawa M, Sasaki A, et al. Molecular epidemiology of respiratory syncytial virus infections among children with acute respiratory symptoms in a community over three seasons. J Clin Microbiol. 2005;43:36-40. Medline:15634948 doi:10.1128/JCM.43.1.36-40.2005

30 Zlateva KT, Vijgen L, Dekeersmaeker N, Naranjo C, Van Ranst M. Subgroup prevalence and genotype circulation patterns of human respiratory syncytial virus in Belgium during ten successive epidemic seasons. J Clin Microbiol. 2007;45:3022-30. Medline:17609323 doi:10.1128/JCM.00339-07

31 Mahony JB. Nucleic acid amplification-based diagnosis of respiratory virus infections. Expert Rev Anti Infect Ther. 2010;8:1273-92. Medline:21073292 doi:10.1586/eri.10.121

32 Beck ET, Henrickson KJ. Molecular diagnosis of respiratory viruses. Future Microbiol. 2010;5:901-16. Medline:20521935 doi: $10.2217 / \mathrm{fmb} .10 .48$

33 Mahony JB. Detection of respiratory viruses by molecular methods. Clin Microbiol Rev. 2008;21:716-47. Medline:18854489 doi:10.1128/CMR.00037-07

34 Sutton AJ, Abrams KR, Jones DR, Sheldon TA, Song F. Methods for meta-analysis in medical research. Chicester, UK: John Wiley \& Sons, Ltd. 2000. 